\title{
The Influence of Entrepreneurship Training on Profit Gaps amongst Young Male and Female Entrepreneurs in Congo
}

\author{
Ted Cléophane Ngassa \\ Marien Ngouabi University, Faculty of Economic Sciences, Brazzaville, Congo \\ Email: tedngassa@gmail.com, ted.ngassa@umng.cg
}

How to cite this paper: Ngassa, T. C. (2021). The Influence of Entrepreneurship Training on Profit Gaps amongst Young Male and Female Entrepreneurs in Congo. Modern Economy, 12, 1092-1104. https://doi.org/10.4236/me.2021.126057

Received: May 10, 2021

Accepted: June 22, 2021

Published: June 25, 2021

Copyright $\odot 2021$ by author(s) and Scientific Research Publishing Inc. This work is licensed under the Creative Commons Attribution International License (CC BY 4.0).

http://creativecommons.org/licenses/by/4.0/

\begin{abstract}
Entrepreneurship training is often cited as a key factor in analyses of job creation. However, its role in explaining the profit generated by the jobs created has been rarely discussed in the literature. The objective of this article is to verify whether the profit gaps observed between young male and female entrepreneurs in Congo are explained by entrepreneurial training. Based on data from a survey related to the Employability Skills Development Project (ESDP) conducted in Congo in 2015 by the World Bank (WB) and the use of Oaxaca (1973) \& Blinder (1973) decomposition, the results indicate, on the one hand, that there is a profit gap. On the other hand, entrepreneurship training explains $7.1 \%$ of this gap. These results imply the need, on the one hand, for entrepreneurship training and, on the other hand, for the promotion of an entrepreneurial culture.
\end{abstract}

\section{Keywords}

Entrepreneurship Education, Profit Gaps, Decomposition

\section{Introduction}

The economic literature on the labor market has argued that the labor market in developing countries is characterized by self-employment, particularly in the informal sector. This reality is often seen as the result not only of a productive apparatus that creates few formal jobs but also of a weak entrepreneurial culture among young people (Deon \& Fox, 2014). Such a perspective shows that entrepreneurship training is a determinant of employability and constitutes, along with other factors (education, social capital, access to credit), an important determinant of job creation and poverty reduction, particularly among youth (Wan, 2017). In the same vein, Doumbouya (2011) argues that the dynamics 
among businesses created in Africa are affected by an organizational problem. These created enterprises, for the most part, struggle to survive (Deon \& Fox, 2014).

In an attempt to explain the failure of these businesses, several causes have been mentioned in the literature. Deon \& Fox (2014) point out that approximately $70 \%$ of small businesses fail due to a lack of professional entrepreneurial management expertise. Vesper (1990) finds that $10 \%$ of firms survive due to entrepreneurial management. Scheeren \& Bosker (1997) or Boldureanu et al. (2020) argue that education alone is not enough to guarantee sustainability and improve profits, but that education must be combined with good organization within the company. Now, this good organization is developed through the practice of entrepreneurial competence (Valdivia, 2015), which in turn depends on entrepreneurship training. The different arguments above seem to show the influence of entrepreneurship training on the performance of the firm and therefore on profit. However, the question that can be asked is whether entrepreneurship training explains the profit differentials observed among the self-employed.

Building on Boldureanu et al. (2020) thesis, this research, compared to previous research that has focused on education, attempts to test whether the observed profit gaps between young male and female entrepreneurs are related to entrepreneurship training. This research proposes the idea that Entrepreneurship training explains the observed profit gaps between young (male and female) entrepreneurs. To test this hypothesis, this research uses the Congo as a field. Two main elements justify the choice of this field: 1) its context is similar to that of other developing countries, particularly those in sub-Saharan Africa, where labor markets are dominated by self-employment, especially in the informal sector, and 2) its low proportion of young people who have received entrepreneurship training (less than 30\% according to the World Bank report on the Employability Skills Development Project (ESDP) in Congo).

In testing the research hypothesis, this research contributes to the theoretical level. On the one hand, this research complements existing work by analyzing a factor that has been rarely addressed in a general way and almost never in the context of sub-Saharan African countries, particularly the Congo. On the other hand, this research analyzes the profit gap by using the method of Oaxaca (1973) \& Blinder (1973) while taking into account the double potential endogeneity due, first, to the decision to participate or not in the labor market and, second, to the decision to be an entrepreneur rather than a salaried worker.

In addition to the introduction and conclusion, this research includes a literature review, discusses the methodology and presents the results.

\section{Review of the Literature}

Theoretical and empirical work on the relationship between entrepreneurship training and profit is generally oriented towards the value creation or growth of the firm (Kirchhoff, 1994). 


\subsection{Theoretical Perspectives}

On the theoretical level, few studies have directly analyzed the relationship between entrepreneurship training and profit. However, the relationship can be analyzed indirectly, mainly based on the approaches developed by Morris (1998), Carree \& Thurik (2005) and Ahmad \& Hoffman (2007). According to Morris (1998), entrepreneurship is a process of transforming inputs into outputs. Inputs represent a set of factors, such as opportunities and the ability of individuals to seize these opportunities and to engage in business in a more or less favorable organizational context. Outputs, on the other hand, are characterized by the number of applications and their effects on the market, by innovation or by the general action of companies within the economy. In the presence of inputs and outputs, Morris' (1998) approach shows that through entrepreneurship training, an entrepreneur can innovate and thus promote profit generation and ultimately employment and income growth. A similar argument was developed by Weick (1996), for whom entrepreneurship training plays a key role in the accumulation of new knowledge as well as in the integration and adaptation to new situations.

In contrast to Morris' (1998) approach, Carree \& Thurik's (2005) approach considers profit generation to be the result of a transformation of the entrepreneur's personal qualities and ambitions into action. For these authors, entrepreneurial activity starts at the individual level but takes shape at the organizational level, especially when the environment is favorable. Carree \& Thurik's (2005) argument assumes that in order to move from the individual to the organizational level, the entrepreneur must demonstrate an understanding of entrepreneurial culture. However, this understanding of entrepreneurial culture is mainly acquired through entrepreneurship training. By implication, this means that profit generation is achieved through entrepreneurship training.

Ahmad \& Hoffman (2007) differ from Morris (1998) and Carree \& Thurik (2005) in that they view entrepreneurial capabilities (entrepreneurial training and experience; entrepreneurship and business education) as the primary factors that explain investment in research and development. For Ahmad \& Hoffman (2007), these entrepreneurial capabilities promote investment not only in research and development but also in entrepreneurial culture, which in turn helps provide access to funding. Access to finance gives the entrepreneur the opportunity to invest in production in order to improve production and thus increase his or her profit level.

However, the analyses of Morris (1998), Carree \& Thurik (2005) and Ahmad \& Hoffman (2007) are not the consensus. Indeed, Van Praag \& Cramer (2001) argue that entrepreneurial ability is conditioned primarily by the level of education in general and not by entrepreneurship training alone, as emphasized by Ahmad \& Hoffman (2007) and others (Morris, 1998; Carree \& Thurik, 2005). Van Praag \& Cramer's (2001) argument assumes that the skills acquired through entrepreneurship training depend on the entrepreneur's level of education. Van 
Praag \& Cramer's (2001) thesis implies a dependence of entrepreneurship training on educational attainment.

\subsection{Empirical Review}

The empirical literature also includes research that has analyzed the effects of entrepreneurship training on profit. Some research concludes that its effects on profit are positive, while others conclude that entrepreneurship training has no effect on profit.

Regarding the research in which the effects are positive, the work of Berge et al. (2009), Valdivia (2015) and Elert, Andersson, \& Wennberg (2014) can be cited. Berge et al. (2009), in comparing the effectiveness of a training intervention versus a financial subsidy intervention from a randomized evaluation in Tanzania, find that participation in entrepreneurial training significantly increases total sales and the profit from men's activities. However, their results indicate that there is no impact on profits for those who received the financial grant alone.

Regarding the work of Valdivia (2015), the results obtained after a randomized evaluation of a training program in Peru show that the effects of general entrepreneurship training on profit are sustained over time (15 months). Elert, Andersson, \& Wennberg (2014), using Swedish data, evaluate the impact of entrepreneurial training on entrepreneurial performance using a matching approach. They find a significant and positive effect of entrepreneurial training on entrepreneurial performance but not on the length of time the firm created by the entrepreneur exists.

In contrast to the work presented above that identifies positive effects, the research of Bruhn \& Zia (2013) and Karlan, Knight, \& Udry (2012) concludes that there is no link between entrepreneurship training and profit. Indeed, the results of Bruhn \& Zia's (2013) work show that short-term entrepreneurial and financial training have no effect on the profits and sales of the recipients of said training, nor on business survival or creation.

Using data from a program targeting microentrepreneurs in Ghana, Karlan, Knight, \& Udry (2012) use a randomized evaluation. They find that receiving only a financial grant or receiving a grant combined with entrepreneurship training does not have significant effects on the profitability of the activities. The authors try to explain this result through constraints in skills, particularly in terms of the choice of management practices to adopt.

Using a sample of 3457 individuals in Peru and a randomized evaluation as well as the double difference method, Karlan \& Valdivia (2011) find in their research that entrepreneurship training has no effect on the marginal profits of the main product of the entrepreneur's business. Similarly, the results of Mano et al. (2011) indicate that the observed effects of entrepreneurship training on sales and profits are not significant.

The review of the literature implies two conclusions. First, entrepreneurship 
training has mixed effects on profits insofar as in some studies, these effects are positive, while in others, entrepreneurship education has no effect on profit. Second, entrepreneurship training seems to be related to the level of education of the entrepreneur, hence the need to take into account the double potential endogeneity. Indeed, young entrepreneurs in Africa mainly work in the informal sector of the labor market and generally have a primary or secondary education. This observation shows the importance of taking into account not only the decision of whether to participate in the labor market but also and above all the choice between being an entrepreneur and being a salaried worker, bearing in mind that salaried work, particularly in the formal sector of the labor market, is often linked to one's level of education.

\section{Methodology}

In this section, two items are presented: 1) the data and the estimation model and 2) the analysis variables.

\subsection{Data and Estimation Model}

The data used in this article are from a survey conducted in 2015 in Congo by the World Bank as part of the Employability Skills Development Project (ESDP). The sample surveyed includes 880 young people. The choice of this dataset is justified by the fact that it provides a wider range of information appropriate for the study of youth entrepreneurship than other datasets on employment issues available in Congo, notably the surveys on employment and the informal sector in Congo (EISC). In addition, the ESDP database has the advantage over other employment surveys of being the most recent available. This analysis focuses on the 195 young people working for their own business. This choice is justified by the fact that entrepreneurship in developing countries is mainly characterized by self-employment. Self-employed workers represent the category of workers for which it seems appropriate to analyze entrepreneurship.

The model chosen for this article is a three-stage model, inspired by the work of Njifen \& Pemboura (2020). This three-stage model is an extension of Heckman's (1979) two-stage model and allows for the correction of the double endogeneity related to whether or not one participates in the labor market and whether or not one is an entrepreneur. In the first stage, the following so-called labor market participation equation is estimated:

$$
Y=\alpha T+\varepsilon_{i}
$$

where $Y$ is the explained variable and $T$ represents the vector of explanatory variables (age, gender, education level, etc.) and $\alpha$ the vector of estimated coefficients for the variables in the vector T. $Y=1$ if the individual works and 0 otherwise.

The second-stage equation is the decision to engage in self-employment.

$$
V=\beta M+\mathrm{imr}+\varepsilon_{i}
$$


where $V$ is the explained variable and $M$ represents the vector of explanatory variables (age, gender, financial aid, entrepreneurship training, having at least one entrepreneurial parent, etc.) and $\beta$ the vector of estimated coefficients for the variables in the vector $M$. imr is the inverse Mills ratio obtained after the estimation of Equation (1). $V=1$ if the individual is self-employed and 0 otherwise.

The profit equation that represents the third step can be written as follows:

$$
\ln (\text { profit })=\lambda_{1} X_{1}+\lambda_{2} X_{2}+\mathrm{imr}+\mathrm{imrl}+\varepsilon_{i}
$$

where $\ln$ (profit) is the logarithm of profit, $X_{1}$ and $X_{2}$ are the vectors of the individual characteristics of the entrepreneur (age, gender, etc.) and of firm-related variables (firm size, number of working days), respectively. imr and imrl are the inverse mill ratios obtained from the estimates in Equations (1) and (2), and $\varepsilon_{i}$ is the vector of error terms, which are assumed to follow a normal distribution.

It should be noted that Equations (1) and (2) are probit models estimated by maximum likelihood, whereas Equation (3) is a linear model estimated by ordinary least squares (OLS). However, Equation (2) is estimated using only the data for which $Y=1$, i.e., those who work. Similarly, Equation (3) is estimated using only the data for which $V=1$, i.e., only those who are self-employed.

The method used to verify the existence of a profit gap between the two groups (G1: female and G2: male) is inspired by the work of Oaxaca (1973) \& Blinder (1973). The decomposition method developed by these authors, compared to matching methods or ordinary least squares (OLS), has the advantage of making it possible to calculate the discriminatory share of the total profit gap between two groups. It is a decomposition of the differences in means. This is the main advantage that justifies the choice of this method over the other methods mentioned above. However, this method is limited. It does not allow for a decomposition of the differences at all profit levels, as is the case with a quantile decomposition. This limitation does not affect the quality of the estimates in the sense that the purpose of this research is to show that entrepreneurship training explains the profit gap between men and women. The method chosen (Oaxaca (1973) \& Blinder (1973) decomposition) therefore makes it possible to meet this objective.

The purpose of the Oaxaca (1973) \& Blinder (1973) decomposition is to compare:

$$
E\left(Y_{G 1}\right)-E\left(Y_{G 2}\right)
$$

where $Y_{G 1}$ is the wage of group G1 and $Y_{G 2}$ is the wage of group G2. In this paper, wages is replaced by profits. Taking the conditional expectations, we obtain:

$$
E\left(Y_{G 1}\right)=E\left[E\left(Y_{G 1} / X^{G 1}\right)\right]=\hat{\beta}_{1}^{G 1} \bar{X}^{G 1}
$$

and

$$
E\left(Y_{G 2}\right)=E\left[E\left(Y_{G 2} / X^{G 2}\right)\right]=\hat{\beta}_{1}^{G 2} \bar{X}^{G 2}
$$

If we propose a counterfactual such as:

$$
E\left(Y_{c}\right)=\hat{\beta}_{1}^{G 2} \bar{X}^{G 1}
$$


we obtain:

$$
E\left(Y_{G 1}\right)-E\left(Y_{G 2}\right)=\left[E\left(Y_{G 1}\right)-E\left(Y_{c}\right)\right]+\left[E\left(Y_{c}\right)-E\left(Y_{G 2}\right)\right]
$$

which is equivalent to the equation:

$$
E\left(Y_{G 1}\right)-E\left(Y_{G 2}\right)=\left(\hat{\beta}_{1}^{G 1}-\hat{\beta}_{1}^{G 2}\right) \bar{X}^{G 1}+\hat{\beta}_{1}^{G 1}\left(\bar{X}^{G 1}-\bar{X}^{G 2}\right)
$$

The first part of the equation, $\left(\hat{\beta}_{1}^{G 1}-\hat{\beta}_{1}^{G 2}\right) \bar{X}^{G 1}$, is the difference in structure, i.e., the difference in returns: this is the unexplained part of the decomposition, the part that assesses the presence of discrimination.

The second part of the equation, $\hat{\beta}_{1}^{G 1}\left(\bar{X}^{G 1}-\bar{X}^{G 2}\right)$, is the difference in the characteristics of the individuals (the compositional effects): this is the explained part of the decomposition.

By taking into account the fact that entrepreneurship training is likely to influence the choice to be an entrepreneur (i.e., to create one's own job) rather than a wage earner, the effect of entrepreneurship education on choice becomes ambiguous. This ambiguity leads to the recognition of the endogeneity in the choice of individuals to become entrepreneurs rather than wage earners. Failure to account for the fact that (specific) unobservable characteristics influence this choice could bias estimates of the returns to entrepreneurship training.

After correcting for the endogeneity bias due to this double selection, equation (9) becomes:

$$
\begin{aligned}
E\left(Y_{G 1}\right)-E\left(Y_{G 2}\right)= & \left(\hat{\beta}_{1}^{G 1}-\hat{\beta}_{1}^{G 2}\right) \bar{X}^{G 1}+\hat{\beta}_{1}^{G 1}\left(\bar{X}^{G 1}-\bar{X}^{G 2}\right) \\
& +\left(\widehat{\theta_{G 1}} \widehat{\lambda_{G 1}}-\widehat{\theta_{G 2}} \widehat{\lambda_{G 2}}\right)+\left(\widehat{\sigma_{G 1}} \widehat{\rho_{G 1}}-\widehat{\sigma_{G 2}} \widehat{\rho_{G 2}}\right)
\end{aligned}
$$

where the parts $\left(\widehat{\theta_{G 1}} \widehat{\lambda_{G 1}}-\widehat{\theta_{G 2}} \widehat{\lambda_{G 2}}\right)$ and $\left(\widehat{\sigma_{G 1}} \widehat{\rho_{G 1}}-\widehat{\sigma_{G 2}} \widehat{\rho_{G 2}}\right)$ represent the effects of the potential selection biases.

\subsection{Analysis Variables}

From the theoretical literature and the empirical works consulted, the following variables are chosen for Equation (3), which is the equation of interest in this research:

lnProfit: This is the logarithm of the profit earned. Profit is the total revenue generated by the entrepreneurial activity last month, after all expenses have been paid (including employee salaries). This is the dependent variable.

Entrepreneurship training: This variable represents whether or not the individuals has received entrepreneurship training. It is a dichotomous variable. Ahmad \& Hoffman (2007) argue that entrepreneurship training equips the entrepreneur with several skills that allow him or her to innovate as well as to access credit. Innovation and access to credit in turn influence profit. This variable is expected to have a positive influence $(+)$ on profit.

Gender: This is a dichotomous variable that indicates whether the owner of the firm is male or female. The choice of this variable is supported by Valdivia's (2015) argument that female entrepreneurs earn lower profits than males, which 
implies a negative effect (-) on profit.

Education: This is the highest level of education achieved by the entrepreneur. The entrepreneur's level of education positively influences (+) profit. Indeed, according to Van Praag \& Cramer (2001), the level of education conditions the acquisition of skills, which impacts entrepreneurial training and consequently the company's performance and therefore its profit.

Age: This is the age of the entrepreneur at the time of the survey. Age has a positive effect $(+)$ on profit in the sense that age is positively correlated with the duration of employment, which in turn positively influences profit.

Number of working days: This is the number of days worked in the last month. This variable also has a positive effect $(+)$ on profit insofar as it is positively related to the number of hours worked, which in turn has a positive effect on profit.

Size of the firm: This is the number of people working in the firm. The expected effect is negative (-). Indeed, in developing countries, entrepreneurship is dominated by the creation of small enterprises. As the size of the firm increases, costs become greater and profits tend to decrease.

Duration of the activity: This is the number of years since the entrepreneur entered his or her current job. The expected effect is positive (+) because the duration of the activity can be translated into professional experience.

\section{Results}

Section 3.1 first presents the descriptive statistics. In the second part, the results of the econometric estimations are presented and discussed.

\subsection{Descriptive Statistics}

The description of the data shows that among the young people who have received training in entrepreneurship, $38 \%$ are female, approximately $39 \%$ are able to define objectives in their activity management, $21.05 \%$ keep a register to manage their inventory and $71.58 \%$ control the production costs of their goods and/or services. Other descriptive statistics are presented in the table below:

The statistics presented in Table 1 show that, on average, young people who have received entrepreneurship training earn higher profits than young people who have not received such training. The difference is approximately 19,105 FCFA. The average age is almost identical between the two categories of youth since it is 23.19 years for individuals in the first category and 23.45 years for those in the second. On the other hand, youth in the first category have been in their jobs longer than youth in the second category. These descriptive statistics allow us to see that the young people in the first category realize, on average, higher profits than the young people in the second category.

\subsection{Estimation Results}

Analyzing the results of the regression requires checking the validity of the mod- 
el. For this purpose, Fisher's F test is used to assess the overall quality of the model estimated in this article. According to the statistics presented in Table 2 below, the model is globally significant at the $1 \%$ level; i.e., there is a dependency relationship between profit and the explanatory variables. Furthermore, the estimation results show that the profit equation is related to both the decision to work and the decision to be an entrepreneur because the inverse Mills ratios (imrs) are significant at the 5\% level.

Table 1. Descriptive statistics for the variables age, profit and duration of the activity.

\begin{tabular}{|c|c|c|c|c|c|c|}
\hline & \multicolumn{3}{|c|}{ Trained in entrepreneurship } & \multicolumn{3}{|c|}{ Not trained in entrepreneurship } \\
\hline & $\begin{array}{c}\text { Mean } \\
\text { (Std. Err.) }\end{array}$ & $\min$ & $\max$ & $\begin{array}{c}\text { Mean } \\
\text { (Std. Err.) }\end{array}$ & $\min$ & $\max$ \\
\hline \multirow[t]{2}{*}{ Monthly Profit (FCFA) } & $39,482.620$ & 0 & 180,000 & $20,377.170$ & 0 & 230,000 \\
\hline & $(42,632.670)$ & & & $(23,014.540)$ & & \\
\hline \multirow[t]{2}{*}{ Age } & 23.190 & 16 & 29 & 23.450 & 17 & 30 \\
\hline & $(2.745)$ & & & $(3.364)$ & & \\
\hline \multirow[t]{2}{*}{ Duration of the activity (in years) } & 1.630 & 0 & 8 & 1.404 & 0 & 10 \\
\hline & $(1.982)$ & & & $(2.125)$ & & \\
\hline Number of observations & 81 & & & 113 & & \\
\hline
\end{tabular}

Source: Author's calculations based on ESDP survey data, Congo 2015.

Table 2. Regression results.

\begin{tabular}{|c|c|c|c|}
\hline $\ln$ Profit & Coef. & Std. Err. & $p$-value \\
\hline Age & 0.505 & 0.336 & 0.133 \\
\hline $\mathrm{Age}^{2}$ & -0.010 & 0.007 & 0.163 \\
\hline Entrepreneurship training & $0.045^{\star *}$ & 0.023 & 0.048 \\
\hline Size of the firm & -0.557 & 0.951 & 0.558 \\
\hline Number of working days & $0.377^{\star *}$ & 0.189 & 0.046 \\
\hline Duration of the activity & $0.310^{\star * *}$ & 0.087 & 0.000 \\
\hline Education & $0.415^{\star *}$ & 0.163 & 0.011 \\
\hline Gender & $-0.068^{\star}$ & 0.041 & 0.098 \\
\hline $\mathrm{imr}$ & $0.843^{\star *}$ & 0.384 & 0.028 \\
\hline imr1 & $-0.226^{\star *}$ & 0.114 & 0.048 \\
\hline Constant & 1.420 & 3.966 & 0.720 \\
\hline Number of obs & & \multicolumn{2}{|c|}{178} \\
\hline Fisher & & \multicolumn{2}{|c|}{5.030} \\
\hline Prob $>$ F & & \multicolumn{2}{|c|}{$0.000^{* * *}$} \\
\hline
\end{tabular}

Source: Author's calculations based on ESDP survey data, Congo $2015 .{ }^{\star * *} p<0.01,{ }^{\star *} p<0.05,{ }^{\star} p<0.1$. 
The regression results show that entrepreneurship training, number of days worked, length of time in business and education have significant and positive effects on profit. Having received entrepreneurship training is therefore rewarded more than not having done so. The same is true for education. Indeed, the results indicate that an additional year of education increases profit by an average of 0.415 percentage points. Furthermore, the results reveal that being female negatively affects profit compared to being male.

The results obtained using OLS indicate the presence of discrimination between those with and without entrepreneurship training. However, OLS estimation can be sensitive to differences in the distributions. Due to this limitation, in the following, Table 3 presents the results obtained from the Oaxaca (1973) \& Blinder (1973) decomposition, which seems to be the appropriate method for estimating this type of problem.

The Oaxaca \& Blinder decomposition here predicts a $55.6 \%$ profit gap between young male entrepreneurs and young female entrepreneurs. The difference in characteristics (the explained component) between the two groups explains $15.8 \%$ of the profit gap. In addition, the difference in entrepreneurship training between men and women explains $7.1 \%$ of the difference. This result shows that the profit gap between male and female entrepreneurs is related to entrepreneurship education. The unexplained, i.e., discriminatory, share is $39.8 \%$. This indicates that profit discrimination against young female entrepreneurs leads to a profit gap with young male entrepreneurs of approximately $39.8 \%$ (Table A).

Table 3. Oaxaca \& Blinder decomposition between men and women.

\begin{tabular}{|c|c|c|c|}
\hline $\ln$ Profit & Coef. & Std. Err. & $p$-value \\
\hline \multicolumn{4}{|l|}{ Adjusted prediction } \\
\hline Prediction for men & $11.290^{\star * *}$ & 1.374 & 0.000 \\
\hline Prediction for women & $10.735^{\star * *}$ & 0.747 & 0.000 \\
\hline Difference & $0.556^{\star *}$ & 0.228 & 0.014 \\
\hline Explained part & $0.158^{*}$ & 0.090 & 0.079 \\
\hline Unexplained part & $0.398^{\star}$ & 0.210 & 0.054 \\
\hline \multicolumn{4}{|l|}{ Explained part } \\
\hline Age & 0.007 & 0.018 & 0.685 \\
\hline $\mathrm{Age}^{2}$ & -0.015 & 0.032 & 0.640 \\
\hline Entrepreneurship training & $0.071^{\star}$ & 0.037 & 0.058 \\
\hline Size of the firm & -0.001 & 0.047 & 0.979 \\
\hline Number of working days & 0.000 & 0.025 & 0.988 \\
\hline Duration of the activity & 0.001 & 0.015 & 0.931 \\
\hline Education & $0.098^{*}$ & 0.054 & 0.071 \\
\hline
\end{tabular}

Source: Author's calculations based on ESDP survey data, Congo 2015. ${ }^{* *} p<0.01,{ }^{* *} p<0.05,{ }^{*} p<0.1$. 
The results of this research are in line with the work of Elert, Andersson, \& Wennberg (2014), who show that entrepreneurship training has an effect on firm performance. Similar results were obtained by Valdivia (2015). Berge et al. (2009) also showed in their work that entrepreneurship training affects profit.

In the Congolese context, the results found can be explained by the fact that few young people are trained in entrepreneurship (INS, 2011). In the Congo, entrepreneurship training is expensive, which makes it difficult for everyone to access such training. In addition, young Congolese entrepreneurs most often utilize "traditional" entrepreneurial skills acquired on the job from their parents or their immediate environment. These "traditional" skills are generally not in line with the new entrepreneurial paradigm, which is based on new models of opportunity identification and management practices. Moreover, it has been proven in several studies (Carree \& Thurik, 2005; Ahmad \& Hoffman, 2007) that entrepreneurship training provides entrepreneurs with several skills that can help them identify profit opportunities, among other things. Based on this last argument, it is possible to observe a profit gap due to a gap in entrepreneurship training between young male entrepreneurs and young female entrepreneurs in Congo.

\section{Conclusion}

The purpose of this article was to verify whether the profit gaps observed among young entrepreneurs in Congo are related to entrepreneurial training. To carry out this verification, a three-stage model was used, followed by Oaxaca (1973) \& Blinder (1973) decomposition. The results obtained from the estimations indicate that there is a profit gap of approximately $55.6 \%$ between young male entrepreneurs and young female entrepreneurs. In addition, these results reflect that discrimination accounts for approximately $39.8 \%$ of the gap between young women entrepreneurs and young men entrepreneurs. The results also reveal that entrepreneurship training explains $7.1 \%$ of the profit gap between men and women.

The results obtained imply that in addition to education, young people need to be trained in entrepreneurship in order to have the skills needed to guarantee both their profit margin and the dynamics and survival of their business. The results of this research also mean that agencies, mainly public agencies in charge of employment issues, should place special importance on entrepreneurship training in order to promote an entrepreneurial culture.

This article has some shortcomings. The main shortcoming is that the paper shows that there is a large unexplained gap in the profit of young male entrepreneurs and that of young female entrepreneurs but does not test whether this is true at all levels of profit. This limitation is an opportunity for future research in that it opens up the possibility of conducting new research by, for example, mobilizing the unconditional quantile regressions of Firpo, Fortin, \& Lemieux (2009) to test for a gap at all levels of profit. 


\section{Conflicts of Interest}

The author declares no conflicts of interest regarding the publication of this paper.

\section{References}

Ahmad, N., \& Hoffman, A. (2007). A Framewok for Addressing and Measuring Entrepreneurship. Paris: OCDE, Entrepreneurship Indicators Steering Group. https://doi.org/10.2139/ssrn.1090374

Berge, L., Bjorvatn, K., \& Tungodden, B. (2009). Teaching Entrepreneurship to Microentrepreneurs: Evidence from a Field Experiment in Tanzania. Working Paper.

Blinder, A. (1973). Wage Discrimination: Reduced Form and Structural Estimates. The Journal of Human Resources, 8, 436-455. https://doi.org/10.2307/144855

Boldureanu, G., Ionescu, A. M., Bercu, A., Bedrule-Grigoruță, M. V., \& Boldureanu, D. (2020). Entrepreneurship Education through Successful Entrepreneurial Models in Higher Education Institutions. Sustainability, 12, 1267. https://doi.org/10.3390/su12031267

Bruhn, M., \& Zia, B. (2013). Stimulating Managerial Capital in Emerging Markets: The Impact of Business Training for Young Entrepreneurs. Journal of Development Effectiveness, 5, 232-266. https://doi.org/10.1080/19439342.2013.780090

Carree, M., \& Thurik, R. (2005). Understanding the Role of Entrepreneurship for Economic Growth. Rotterdam: Centre for Advanced Small Business Economics, Rotterdam School of Economics, Erasmus University.

Deon, F., \& Fox, L. (2014). Youth Employment in Sub-Saharan Africa. Africa Development Series. Washington, DC: World Bank.

Doumbouya, M. L. (2011). Survie entrepreneuriale en Afrique: Le cas des entreprises guinéennes. Mondes en Développement, 2011/3 (No. 155), 125-140.

https://doi.org/10.3917/med.155.0125

Elert, N., Andersson, F. W., \& Wennberg, K. (2014). The Impact of Entrepreneurship Education in High School on Long-Term Entrepreneurial Performance. Journal of Economic Behavior and Organization, 111, 209-223.

https://doi.org/10.1016/j.jebo.2014.12.020

Firpo, S., N., Fortin, M., \& Lemieux, T. (2009). Unconditional Quantile Regressions. Econometrica, 77, 953-73. https://doi.org/10.3982/ECTA6822

Heckman, J. (1979). Sample Selection Bias as a Specification Error. Econometrica, 47, 153-163. https://doi.org/10.2307/1912352

Institut National des Statistiques (INS) (2011). Enquête sur l'Emploi et le Secteur Informel (EESIC), Phase 1 (452 p). Brazzaville: Rapport d'analyse: Institut National des Statistiques.

Karlan, D., \& Valdivia, M. (2011). Teaching Entrepreneurship: Impact of Business Training on Microfinance Clients and Institutions. The Review of Economics and Statistics, 93, 510-527. https://doi.org/10.1162/REST a 00074

Karlan, D., Knight, R., \& Udry, C. R. (2012). Hoping to Win, Expected to Lose: Theory and Lessons on Micro Enterprise Development. NBER, Working Paper (November 2012). https://doi.org/10.3386/w18325

Kirchhoff, B. A. (1994). Entrepreneurship and Dynamic Capitalism: The Economics of Business Firm Formation and Growth. Westport, CT: Praeger.

Mano, Y., Iddrisu, A., Yoshino, Y., \& Sonobe, T. (2011). How Can Micro and Small En- 
terprises in Sub-Saharan Africa Become More Productive? The Impacts of Experimental Basic Managerial Training. Policy Research Working Paper.

https://doi.org/10.1596/1813-9450-5755

Morris, M. H. (1998). Entrepreneurial Intensity: Sustainable Advantages for Individuals, Organization, and Societies. Westport, CT: Quorum Books.

Njifen, I., \& Pemboura, A. (2020). Hétérogénéité dans les rendements de l'éducation au Cameroun: Une estimation en présence des biais de sélection et d'endogénéité. Region et Developpement, 52, 105-126.

https://ideas.repec.org/a/tou/journl/v52y2020p105-126.html

Oaxaca, R. (1973). Male-Female Wage Differentials in Urban Labor Markets. International Economic Review, 14, 693-709. https://doi.org/10.2307/2525981

Scheeren, J., \& Bosker, R. J. (1997). The Foundation of Education Effectiveness. Oxford: Redwood Books Ltd.

Valdivia, M. (2015). Business Training plus for Female Entrepreneurship? Short and Mediumterm Experimental Evidence from Peru. Journal of Development Economics, 113, 33-51. https://doi.org/10.1016/j.jdeveco.2014.10.005

Van Praag, C. M., \& Cramer, J. S. (2001). The Roots of Entrepreneurship and Labour Demand: Individual Ability and Low Risk Aversion. Economica, 68, 45-62. https://doi.org/10.1111/1468-0335.00232

Vesper, K. (1990). New Venture Strategies. Englewood Cliffs, NJ: Prentice Hall.

Wan, L. Y. (2017). Literature Review about the Influence Factors of Self-Employment. American Journal of Industrial and Business Management, 7, 79-92. https://doi.org/10.4236/ajibm.2017.72007

Weick, K. E. (1996). Drop Your Tools: An Allegory for Organizational Studies. Administrative Science Quarterly, 41, 301-313. https://doi.org/10.2307/2393722

\section{Annex}

Table A. Oaxaca-Blinder decomposition: Unexplained part.

\begin{tabular}{cccc}
\hline lnProfit & Coef. & Std. Err. & $p$-value \\
\hline Age & 0.660 & 1.031 & 0.731 \\
Age $^{2}$ & -0.869 & 5.185 & 0.954 \\
Entrepreneurship training & $0.185^{* * *}$ & 0.047 & 0.000 \\
Size of the firm & $-1.073^{*}$ & 0.584 & 0.066 \\
Number of working days & $0.060^{* * *}$ & 0.004 & 0.000 \\
Duration of the activity & $-0.287^{* * *}$ & 0.568 & 0.000 \\
Education & $0.164^{* * *}$ & 0.047 & 0.001 \\
Constant & $6.037^{* * *}$ & 1.157 & 0.000 \\
\hline
\end{tabular}

Source: Author's calculations based on ESDP survey data, Congo 2015. ${ }^{* *} p<0.01,{ }^{*} p<0.1$. 